\title{
A ROSA E A MENSAGEM \\ o imaginário grego na poesia de fernando Pessoa
}

\author{
Sonila Morelo*1 \\ Núcleo de Estudos Antigos e Medievais \\ Universidade Federal Minas Gerais
}

\begin{abstract}
RES U M O
A partir de uma leitura comparativa entre a composição de Fernando Pessoa, especialmente de Mensagem, e a poesia grega Arcaica em que encontramos imagens de Afrodite - versos de Hesíodo e Safo sobre o nascimento e as qualidades da deusa -, este artigo tem como objeto de análise a Rosa. Através do diálogo entre história e literatura, a discussão proposta perpassa as semelhanças encontradas entre a Rosa de Mensagem e a deusa Afrodite de Hesíodo e Safo.
\end{abstract}

PALAVRAS-CHAVE

Rosa, Afrodite, Mensagem

objetivo principal deste estudo, apresentado neste artigo, é analisar a obra Mensagem, com ênfase no significado da Rosa, o símbolo fecundo, divino, que surge na aurora, como a descreve Fernando Pessoa. Nosso ponto de partida, para a leitura dos poemas de Pessoa, tem como perspectiva uma comparação entre a imagem da Rosa e a estrela da manhã - ou melhor, a deusa Afrodite -, visto que na tradição portuguesa, especialmente em Camões, ela é reconhecida como guia e protetora dos navegantes que conquistaram o mar e conheceram a terra.

Para construir uma argumentação que sustente a hipótese de que encontramos semelhanças entre a Rosa de Mensagem e a deusa Afrodite, buscaremos na Teogonia e nos fragmentos dos poemas de Safo a história do nascimento da deusa bem como o registro de suas qualidades e atribuições. Depois, retornaremos à Mensagem para encontrar, na estrutura simbólica edificada por Fernando Pessoa, a Rosa e seu significado. Entreposto entre a poesia grega arcaica e a portuguesa do início do século XX, Os

\footnotetext{
*sonilamorelo@hotmail.com

${ }^{1}$ Agradeço ao Teodoro Rennó Assunção, pelo curso e discussões sobre Hesíodo; ao Jacyntho Lins Brandão e Antônio Orlando Lopes Dourado pela leitura crítica do meu texto; ao Mateus H. F. Pereira pelas sugestões sobre história e literatura; à Silvana Maria Pessoa de Oliveira e ao Mario Alex Rosa pelas indicações bibliográficas e diálogos sobre a poesia pessoana. Sou especialmente grata à Tereza Virgínia Ribeiro Barbosa, pela mão sempre estendida, através de seu incentivo e colaboração, durante meu caminhar acadêmico. Contudo, os equívocos, que existirem neste artigo, são de minha responsabilidade.
} 
Lusíadas $^{2}$ - uma chave de leitura para Mensagem - estará presente como suporte para argumentação proposta. Anuentes com Irene Santos, consideramos "(...) inegável que Os Lusíadas é o principal intertexto de Mensagem". ${ }^{3}$ Sendo assim, sempre que necessário, Camões terá espaço nesse diálogo que se propõe entre a composição pessoana e o imaginário poético grego. ${ }^{4}$

$\mathrm{Na}$ memória épica de Hesíodo, a origem da vida e o ordenamento dos espaços ocupados pelas divindades no mundo são temas que compõem o enredo principal da Teogonia. De acordo com esse poeta, primeiro surgiu Caos, isto é, etimologicamente, ${ }^{5}$ uma abertura, um espaço e, em seguida, Gaia, que nos é apresentada como uma sede firme, irresvalável, de amplo peito, Gaia eurýsternos, de todos os imortais que habitam a cabeça do Olimpo nevado, athanáton hoi ékhousi káre niphóentos Olýmpou (v. 116-118). ${ }^{6}$ Logo após, Tártaro, nevoento no fundo do chão de amplas vias e, então, Eros kállistos, o mais belo de todos, lysimelés, o que desliga ou desarticula os membros de todos os deuses e homens (v. 119-122). ${ }^{?}$

Para Vernant,

Gaia é uma base sólida para andar, uma base em que se apoiar; tem formas cheias e densas, uma altura de montanha, uma profundidade subterrânea; não é apenas um solo a partir do qual o edifício do mundo vai se construir; é a mãe, a anciã que gerou tudo o que existe, sob todas as formas e em todos os lugares, com exceção de Caos e de sua linhagem, que constituem uma família de Potências inteiramente separadas das outras. ${ }^{8}$

\footnotetext{
${ }^{2}$ Este será o padrão de citação adotado neste trabalho para a obra em questão, por exemplo, C2. 48, ou seja, canto 2 e estrofe 48, da obra Os Lvsíadas. A grafia será igual da edição presente nas referências bibliográficas.

${ }^{3}$ SANTOS. Poetas do Atlântico. Fernando Pessoa e o modernismo anglo-americano, p. 66. Apesar da afirmativa citada, Irene Ramalho Santos considera que Camões está "discretamente apagado" ou que sua ausência é notória em Mensagem.

${ }^{4} \mathrm{O}$ conceito de imaginário que adotamos como referência para essa análise está presente em Baczko, "Os imaginários sociais constituem outros tantos pontos de referência no vasto sistema simbólico que qualquer coletividade produz e através da qual (...) ela se percepciona (...) designa sua identidade; elabora certa representação de si...”. BACZCO. Imaginação social, p. 309. Bem como em LeGoff, em que "O imaginário pertence ao campo da representação mas ocupa nele a parte não reprodutora, não simplesmente transposta em imagem do espírito, mas criadora, poética no sentido etimológico da palavra (...). Mas, o imaginário, embora ocupando apenas uma fração do território da representação, vai mais além dele. A fantasia - no sentido forte da palavra - arrasta o imaginário para lá da representação, que é apenas intelectual”. LE GOFF. O imaginário Medieval, p. 11-12.

${ }^{5}$ CHANTRAINE. Dictionnaire étymologique de la langue grecque. Histoire des motes, p. 1.246. Caos tem o sentido de espaço infinito.

${ }^{6}$ Os versos da Teogonia serão indicados no corpo do texto.

${ }^{7}$ Segundo Rudhardt, Tártaro, Eros e Caos, em Hesíodo não se constituem como substâncias, mas elementos insólitos; Gaia, por sua vez, quando disforme, indefinida, componente concreto depositado no fundo de Caos, era um elemento neutro, não se opunha, ainda que termo lexical feminino, a nenhum princípio masculino. Nessa ocasião, Eros fez nascer, de Caos, Érebro e Noite, e, de Gaia, Céu e Mar - outros dois elementos concretos masculinos. Pelo diferente, gerado posteriormente, Gaia se tornou feminina. RUDHARDT. Le role d'Eros et d'Aphrodite das les cosmogonies grecques, p. 9.
}

${ }^{8}$ VERNANT. Cosmogonia, p. 244. 
Da Terra, portanto, foi gerado o Céu, ou seja, Urano, por ela e igual a ela, egeínato îson éoutê̂ (v. 126-127). ${ }^{9}$ Gerou também, sem união alguma, as Montanhas - abrigo das Ninfas - e o Mar (v. 129-132). Depois, com Urano, gera dois grupos: seis seres machos, Oceano, Coiós, Crios, Hipérion e Jápeto, e seis fêmeas, Teia, Réia, Thêmis, Memória, Febe e Tétis. O mais novo dos filhos é Crono, hoplótatos, o todo armado, ankilométes, astucioso, de curvo pensar (v. 137), mencionado à parte, como prenúncio de sua ação.

Urano ocultava os filhos na cova da Terra, Gaies en keuthmôni, não permitindo que viessem à luz, pháos ouk aníeske (v. 157). Enquanto Urano sentia prazer, ${ }^{10}$ a Terra stonakhídzeto, isto é, gemia de dor (v. 159) "Em seu próprio benefício, a Terra ocultou seu sofrimento. Esta iniciativa teve o propósito de elaborar e executar a castração de Urano, como maneira de retirá-lo desse lugar." 11 As supostas aceitação e passividade da Terra revelar-se-ão numa perigosa e eficiente estratégia de ação, que colocará fim a essa situação. Então, urdiu dolosa, dolíen, e maligna arte, tékne; criou, poiésasa, rapidamente, ậpsa, o gênero dos metais (v. 160-161). Por causa das ações indignas, aeikéa, ${ }^{12}$ do pai Urano, Crono atende ao apelo de sua mãe, que lhe fornece o ardil: "... pôs-lhe nas mãos a foice dentada" (v. 175). ${ }^{13}$ Ao receber os respingos de sangue de Urano, Gaia gera as Erínias - agentes da justiça -, os Gigantes e as Ninfas. Com atenção especial e riqueza de detalhes, o poeta narra o nascimento de Afrodite, da espuma branca que ejaculava do pênis cortado de Urano e caía no Mar (v. 188-206). Rosa é a cor sugerida por Hesíodo nesse episódio: o vermelho do sangue misturado à espuma branca - do mar e do esperma -, uma aquarela de tons que lembram o céu durante o amanhecer. Eros e Desejo passam a acompanhá-la desde o seu nascimento, na ilha de Chipre. A fertilidade da terra ao receber Afrodite já se evidencia nos seguintes versos, “... venerada bela deusa ao redor relva crescia sob esbeltos pés” (v. 194-195, grifo nosso).

Depois do nascimento de Afrodite, a geração de novos seres ocorrerá através da união intermediada pelo Desejo, diferentemente de como acontecia no princípio com Gaia e Urano. Assim, no imaginário composto por Hesíodo, fica em evidência a

\footnotetext{
${ }^{9}$ Segundo West, Urano e Gaia formam um par complementar referencial nos mitos e na religiosidade dos gregos. Zeus, descendente desse casal, é um deus celeste. Urano aparece neste contexto genealógico e sua participação na Teogonia está quase sempre vinculada à união com a Terra. Como elemento físico, Urano é considerado como um sólido teto do mundo, kálkeos (Ilíada 17.425) ou sidéreos (Odisséia 15. 329); WEST. Hesiod Theogony: Prolegomena and Commentary, p. 198.

${ }^{10}$ Segundo Vernant, Urano, na simplicidade de sua potência primitiva, não conhece nenhuma outra atividade a não ser a sexual (VERNANT. Cosmogonia, p. 249).

${ }^{11}$ WEST. Hesiod Theogony: Prolegomena and Commentary, p. 214-215, tradução nossa. Gaia's suffering is not mentioned for its own sake. It leads her to devise, propose, and arrange the castration which is to take place.

${ }^{12}$ Por duas vezes, a oração: próteros gàr aeikéa mésato érga, "pois ele tramou antes obras indignas"; é mencionada pelo poeta. No v. 166, é a Terra quem a profere, e, no v. 172, Crono. Ao que parece, Hesíodo pretende justificar a ação planejada por Gaia e executada por Crono, repetindo enfaticamente os motivos da castração de Urano.

${ }^{13}$ A relação entre Urano e Gaia é considerada indigna, tanto pela constância e insaciedade de Urano, que não controla seus desejos, quanto pela opressão sofrida por Gaia, que não consegue dar à luz os filhos. Gaia oferece a Crono as possibilidades e oportunidades de instituição do primeiro reinado na esfera divina.
} 
intermediação da tríade divina - Afrodite, Desejo e Eros - nas relações que geram vida. ${ }^{14}$ Portanto, o nascimento da deusa é um acontecimento, dentro da genealogia composta por esse poeta, que demarca uma mudança nas relações divinas. Tal mudança resulta da ação pensada e articulada por $\mathrm{Gaia}^{15}$ e, nesse sentido, temos duas deusas protagonizando o enredo da história contada pelo poeta - a deusa primordial e Afrodite são presenças centrais nos acontecimentos que modificaram as relações de procriação.

Segundo Rudhardt, a castração de Urano não aboliu a sexualidade ou a fecundidade, ela simplesmente definiu as condições de sua existência num mundo em processo de diversificação. Nas novas condições, o Amor continuará a exercer sua função, mas a partir desse momento, através da ação conjugada de Eros e Afrodite. Afirma, ainda, que Eros é o princípio gerador, desde seu surgimento na Teogonia. ${ }^{16}$

Também, de acordo com Vernant,

(...) o nascimento de Afrodite marca o momento em que o processo gerador passa a ser submetido a regras estritas, em que acontecerá, sem confusão e sem excesso, pela união momentânea de dois princípios contrários, masculino e feminino, aproximados pelo desejo, mas mantidos à distância pela oposição de sua natureza. ${ }^{17}$

O imaginário presente na memória composta por Hesíodo revela que Afrodite rege a união entre o feminino e o masculino, o impulso que faz pulsar e irromper a vida humana, animal e vegetal. Além de Eros e Desejo, outras deidades a acompanham, as Horas que regem o ritmo anual da floração e frutificação e as Cárites que se regozijam com as flores, lembra Ragusa. ${ }^{18}$ Afirma, também, que a deusa está relacionada aos elementos da natureza e que esses formam junto com o sagrado e o erotismo uma tríade indissociável no imaginário grego. ${ }^{19}$

Podemos observar na lírica de Safo que os lugares de culto a Afrodite são, especialmente, os jardins, os prados e os bosques; lugares em que a natureza é descrita de maneira exuberante com flores multicoloridas, fontes e árvores. Os versos do Fr. 6 dos "Cantos Cíprios" dizem,

\footnotetext{
${ }^{14}$ Entretanto, os filhos da Noite são gerados sem essa mediação e possuem caracteres de negatividade: Morte, Escárnio, Assassinato, Velhice funesta, Dores, Fome, Eunomia, Guerra, Homicídio, Equívocos, Engano..., e Filóteta (única exceção a essa regra). Nascem, segundo a sequência dada por Hesíodo, logo após a castração de Urano.

${ }^{15}$ Gaia ocupa lugar central nessa trama sobre a origem da vida e o ordenamento dos espaços ocupados pelos deuses e suas respectivas atribuições; as ações desta deusa são caracterizadas pela capacidade de criação de artefatos, tékhne (v. 159); poiésasa (v. 161); astúcia divina, doloteís e conselhos, ennesíeisin (vv. 160 e 494). A Terra, portanto, não é apenas um palco, um cenário, para a grande cena na qual Zeus vence a batalha contra os Titãs, estabelecendo a partir daí uma nova ordem, Gaia é uma potência geradora de vida e suas ações foram eficientes para a definição dos espaços ocupados pelas diferentes divindades de então.

${ }^{16}$ RUDHARDT. Le role d'Eros et d'Aphrodite das les cosmogonies grecques, p. 11, 17.

${ }^{17}$ VERNANT. Cosmogonia, p. 246.

${ }^{18}$ RAGUSA. Fragmentos de uma deusa. A representação de Afrodite na lírica de Safo.

${ }^{19}$ RAGUSA. Fragmentos de uma deusa. A representação de Afrodite na lírica de Safo, p. 214, 218.
} 
Vestes no corpo pôs, que as Cárites e as Horas / lhe fizeram e tingiram com flores primaveris, / as que as Horas portam: açafrão e jacinto e / violeta em botão, e da rosa flor bela / e doce e nectárea, e divinos botões / das flores do narciso e do lírio. Afrodite tais vestes - com flores da estação todas perfumadas - pôs. / E, com as atendentes, a amante dos sorrisos, Afrodite, / tendo trançado guirlandas fragrantes - flores da terra -, / puseram-nas sobre suas cabeças as deusas de radiantes penteados / Ninfas e Cárites, e, junto, a áurea Afrodite - elas / belamente cantando no monte Ida, rico em fontes perenes. ${ }^{20}$

As flores indicam que a ocasião cantada é o início da primavera, momento ideal para deitar sementes na terra e honrar as divindades relacionadas à fecundidade. ${ }^{21}$ Os versos exaltam a reprodução cíclica da natureza, multicoloridas flores enfeitam a roupa de Afrodite, bem como ornamentam as cabeças das deusas; as fontes indicam a fertilidade perpétua da terra no monte Ida e, assim, o cenário e os ritos festivos são desenhados. A rosa é a bela flor, tanto quanto Afrodite, que, segundo a tradição mítica, vencera Hera na disputa que Éris, divina Discórdia, propôs ao colocar em jogo a maçã de ouro e o título da mais bela deusa. ${ }^{22}$ Nos "Cantos Cíprios", a rosa é bela, doce, nectária e os botões de narciso e de lírio estão associados à ambrosia, divinos. ${ }^{23}$ Néctar e ambrosia são alimentos exclusivos dos deuses e, entre as qualidades de Afrodite, temos o doce gozo, o amor e a meiguice, de acordo com Hesíodo (vv. 640, 206).

No fr. 2, Safo compõe em seus versos o seguinte quadro: bosque de macieiras, templo com altar onde se queimam incensos, água que murmura por entre um prado de flores e de rosas, vento que sopra docemente e, enfim, a presença de Afrodite. ${ }^{24}$ Nesse poema, a poeta explora todos os sentidos, observa Ragusa, visão, olfato, audição, tato e paladar permitem ao leitor adentrar esse lugar intensamente sinestésico e perpassado pelo sagrado (vv. 640, p. 206). As macieiras, árvore das rosáceas, produzem a fruta predileta de Afrodite, a maçã; não por acaso, esta fruta está presente nos poemas, cultos e rituais relacionados a essa deidade - nas núpcias, por exemplo. ${ }^{25} \mathrm{E}$ a rosa, flor cara a Afrodite, afirma Giuliana, “... é erótica, pois, para os antigos, ela refletia 'os mistérios

\footnotetext{
${ }^{20}$ RAGUSA. Fragmentos de uma deusa. A representação de Afrodite na lírica de Safo, p. 109-110.

${ }^{21}$ Em Chipre, Afrodite, as Cárites e as Horas são divindades especiais. Segundo Jacqueline Karageorglis, apud RAGUSA. Fragmentos de uma deusa. A representação de Afrodite na lírica de Safo, p. 111-112: "La grande déese de Chypre et son culte", há registros arqueológicos indicando o culto a Afrodite que remontam a 3.000 anos a.C.

${ }^{22}$ Conforme citamos, anteriormente, encontramos a expressão bela deusa na Teogonia de Hesíodo (v. 194).

${ }^{23}$ A palavra ambrosia significa, literalmente, a negação da mortalidade, ou seja, imortalidade; também pode ser traduzida como o manjar dos deuses, ou alimento que proporciona e conserva a imortalidade. Então temos, nos "Cantos Cíprios", o néctar, a bebida dos deuses e a ambrosia, alimento da imortalidade, ambos diretamente relacionados às flores. Segundo Giuliana, na Iliada, Homero relata que Afrodite ungiu o corpo de Heitor com óleo de rosas, imortal (apud RAGUSA. Fragmentos de uma deusa. A representação de Afrodite na lírica de Safo, p. 108-109).

${ }^{24}$ RAGUSA. Fragmentos de uma deusa. A representação de Afrodite na lírica de Safo, p. 426-427.

${ }^{25}$ RAGUSA. Fragmentos de uma deusa. A representação de Afrodite na lírica de Safo, p. 201-202.
} 
carnais da mulher' - idéia viva até hoje - e, portanto, encontraria 'um fundamento na evocação dos poderes' da deusa da paixão". ${ }^{26}$

No poema "Horizonte" Fernando Pessoa evoca, de forma semelhante à composição da natureza de Safo discutida, o mar 'anterior ao dele', onde o longe se abria em flor e os astros, que indicam o sul, brilhavam sobre as naus da iniciação; finalizando com o desejo de "... Buscar na linha fria do horizonte / a árvore, a praia, a flor, a ave, a fonte - / Os beijos merecidos da Verdade". ${ }^{27}$ O poeta evidencia nesses versos que a verdade, com sua letra inicial maiúscula como se grafa um nome próprio, personifica no poema um ser feminino, assim como são os elementos da natureza mencionados e enfatizados através da repetição do artigo. Então, tendo em perspectiva os poemas gregos, compostos no mar anterior ao português, passamos à leitura de Mensagem.

Mensagem é uma obra que possui uma arquitetura especialmente pensada por seu construtor. Com a citação, "Benedictus Dominus Deus Noster Qui Dedit Nobis Signum", Pessoa anuncia o caráter simbólico que ela contém. ${ }^{28} \mathrm{O}$ livro divide-se em três partes: Brasão, Mar português e $O$ Encoberto. A primeira estrutura-se em cinco outras, inspiradas no símbolo de Portugal, sendo a quinta, o Timbre ou Grifo, uma contribuição pessoana.

\footnotetext{
${ }^{26}$ RAGUSA. Fragmentos de uma deusa. A representação de Afrodite na lírica de Safo, p. 219-220. Em outro poema de Safo temos, “... depois do sol posto, a dedirrósea lua... supera todas as estrelas, e sua luz se esparrama por sobre o salso mar e igualmente sobre multifloridos campos. E o orvalho é derramado em beleza, e brotam as rosas e o macio cerefólio e o trevo-mel em flor...", Fr. 96, apud RAGUSA. Fragmentos de uma deusa. A representação de Afrodite na lírica de Safo, p. 434. A lua, que recebe o epíteto de dedirrósea, brododáktulos, faz cair o orvalho que fertiliza a terra e então, brotam as flores, a rosa, bródov, o trevo mel, melílotos, e o cerefólio, ánthruska. A lua, segundo a poeta, derrama sua luz no mar e na terra, nos multifloridos campos. Ainda para Ragusa, "Se a imagem do mar fala do alcance da luz, a dos campos plenos de flores várias fala da terra fertilizada pela influencia lunar (...)" e, assim, é a fertilidade e a beleza que duplamente são enfatizadas com a predominância do tom erótico. A imagem da lua está, de fato, relacionada ao ciclo fértil da natureza, ao ciclo fértil da mulher, por exemplo. De acordo, com a pesquisadora, na épica e na lírica, os epítetos de Afrodite são: eustéphanos, de bela guirlanda, iostéphanos, de violácea guirlanda, poikilóthron, de flóreo manto furta cor, khrusostephés, de áurea guirlanda, polukhrús e khruseè, multiáurea, áurea e auricoroada; e, em Homero, o início da manhã é caracterizado pela presença da Aurora, Eós, que tem os dedos róseos, em Safo ela tem os braços róseos, brodópakhus, de áurea sandália, khrusopédilos e é venerada, pótnia. RAGUSA. Fragmentos de uma deusa. A representação de Afrodite na lírica de Safo, p. 243. Esses epítetos revelam que as rosas e as flores dão o contorno das imagens que dizem sobre fertilidade, natureza e renovação cíclica da vida, imagens que são, na poesia grega antiga, sagradas e femininas. O brilho áureo de Afrodite relaciona-se com sua origem no Oriente e com sua grandeza relativa no céu. Da terra, a lua e Vênus são os únicos astros que podemos enxergar a olho nu, além do sol, durante o dia. Vênus é também conhecida como a estrela D'alva, aquela que nasce no Oriente um pouco antes do sol, na aurora dourada e rosa. Como observa Giuliana Ragusa, a ilha de Chipre está localizada na "... entrecruzilhada desses dois mundos Grécia e Oriente" (RAGUSA. Fragmentos de uma deusa. A representação de Afrodite na lírica de Safo, p. 232), o que diz sobre a origem oriental de Afrodite e sobre o comércio cíprio de metais preciosos - por lá passava o ouro trazido do Oriente para a Grécia.

${ }^{27}$ PESSOA. Mensagem, p. 44.

${ }^{28}$ Para Seabra, a visão patriótica de Fernando Pessoa é “...essencialmente esotérica e messiânica, assumindo um simbolismo poeticamente estruturado na Mensagem". Afirma, ainda, que Mensagem teria a "... natureza de um poema épico representando as navegações portuguesas como provenientes da guerra entre os velhos e os novos deuses e que a Ilíada é o modelo" (SEABRA. Fernando Pessoa ou o poetodrama, p. 152-153).
} 
São partes do Brasão português: Os Campos, com dois poemas expressando uma matemática simbólica da imagem correspondente aos dois campos do brasão. Os Castelos, com sete poemas, tal quanto são os castelos. As Quinas, cinco poemas, como, também, são as quinas e os pontos no interior de cada quina, cinco. ${ }^{29} \mathrm{~A}$ imagem formada pelas quinas é a cruz e foi desenhada no núcleo do brasão, rodeada pelos castelos. A Coroa, com um poema de doze versos. ${ }^{30}$ O Timbre, a quinta parte, com três poemas. "Bellum sine Bello" é o verso que abre essa primeira parte, Brasão.

A segunda parte da obra, Mar Português, é composta por doze poemas ${ }^{31}$ que relatam os feitos dos portugueses no mar e a posse das terras. $O$ mar é o espelho do céu, como lembra Pessoa e, nesse sentido, o acesso ao conhecimento dos antigos - gregos e fenícios, por meio da presença árabe na Península Ibérica, entre outros capítulos da história ocidental -, fez de Portugal o precursor nas navegações que abrem as portas da chamada época moderna. O poema "Fernão de Magalhães", por exemplo, tem exatamente o dobro de doze, e a palavra Terra está escrita como a grafia dos outros deuses. ${ }^{32} \mathrm{O}$ poema "Fernão de Magalhães" só é menor que o "Mostrengo", com vinte e sete versos, mencionando três vezes o nome do El-Rei D. João II para finalizar as suas três estrofes e, ainda, a expressão "três vezes" aparece sete vezes no poema. No poema XII, Prece, Pessoa fala do mar universal, da saudade e do silêncio hostil trazido pela noite, ou a escuridão dos seus dias, e pede ao vento que assopre a chama, a origem da vida, oculta pelo frio morto em cinzas. Mas, se há vida ainda, diz o poeta, ela poderá se reerguer pela mão do vento. Roga na oração uma conquista autêntica de Portugal, “... outra vez conquistemos a Distância - / Do mar ou outra, mas que seja nossa!". 33 "Possessio Maris" é a epígrafe da segunda parte de Mensagem.

A terceira parte, O Encoberto, desdobra-se em outras três. "Os símbolos" com cinco poemas: "D. Sebastião", "O Quinto Império" - com cinco estrofes de cinco versos, em

\footnotetext{
${ }^{29}$ Segundo Camões, os cinco escudos representam os cinco reis mouros vencidos e faz referência aos trinta dinheiros pelos quais Judas vendeu Cristo aos romanos (contando-se duas vezes a quina do meio) (C3. 53-54). Em outro verso, Camões fala dos quatro elementos - fogo, ar, terra e água - e menciona o velho Caos e a guerra dos gigantes (C6.10-13). As cinco quinas podem ser os quatro elementos e a quinta essência e não representam, portanto, os trinta dinheiros; sendo a primeira explicação tão falsa quanto o gesto de Judas. No canto Quinto, Camões traz para sua poesia, de maneira consideravelmente intensa, assuntos sobre os segredos escondidos da natureza, nas escrituras dos antigos filósofos que andaram tantas terras e, por verem segredos delas, contam muitas maravilhas sobre as influências das estrelas e tudo sem mentir, puras verdades, como ele afirma (C5.23, especialmente).

${ }^{30}$ Doze são, também, os meses do ano segundo o calendário solar, definido pelo estudo antigo da astronomia. Tal conhecimento dos astros instrumentalizou a navegação portuguesa e viabilizou a formação do império português, coroando a história de Portugal com a dominação e colonização das terras além-mar.

${ }^{31}$ Quase todos os poemas possuem doze versos, um número de versos múltiplo de seis. Cabe lembrar, também, que a primeira geração de Gaia e Urano é composta por doze filhos, sendo Crono o mais jovem, segundo Hesíodo.

${ }^{32}$ Doze meses é o tempo que a Terra precisa para realizar uma volta completa ao redor do Sol e quatro são as estações do ano. Vinte quatro horas é o tempo que o planeta terra demora a realizar uma rotação no seu próprio eixo, um dia.
}

${ }^{33}$ PESSOA. Mensagem, p. 55. 
que são mencionados os quatro tempos, Grécia, Roma, Cristandade, Europa e o Quinto na perspectiva poética visionária, em que “... A terra será teatro / Do dia claro, que no atro / Da erma noite começou...”34 -, O Desejado, que é Galaaz, mestre da paz, iluminado, terceiro irmão do rei Arthur das lendas de Avalon, que revelará o Santo Graal, As Ilhas Afortunadas ${ }^{35}$ e, por fim, o quinto poema, O Encoberto, que traz o objeto desta discussão, a Rosa. O poema apresenta uma arquitetura que valoriza o número doze, três estrofes com quatro versos; Rosa, Cruz e símbolo são palavras-chave e aparecem três vezes no poema, uma em cada estrofe. O poema diz que a Rosa é o símbolo fecundo, divino e final, que surgirá na aurora, no dia já visto, no sol desperto, na luz do amanhecer ansiosamente esperado, e que a cruz morta do mundo, que é o destino fatal, revelará a vida que é a Rosa, o símbolo encoberto. Se a cruz que está no núcleo do brasão português traz as cinco quinas, com cinco pontos cada uma, esta deve ser a revelação que iluminará a Rosa.

A segunda parte da terceira é formada por Os avisos, que são o conjunto dos três seguintes poemas, "O Bandarra", "Antônio Vieira" e o terceiro em que Fernando Pessoa escreve na primeira pessoa. ${ }^{36} \mathrm{Na}$ terceira parte, a final da obra - terceira da terceira na engenharia da Mensagem -, temos o conjunto de cinco poemas "Noite", "Tormenta", "Calma”, "Antemanhã", e "Nevoeiro", que compõem o enredo de Os tempos. Novamente, o poeta retoma os cinco tempos, Grécia, Roma, Cristandade, Europa e o Quinto. No último poema, ele finaliza assim sua Mensagem: “... Esse fulgor baço de terra / Que é Portugal a entristecer - / Brilho sem luz e sem arder, (...) Ó Portugal, hoje és nevoeiro...”. 37 Afinal, em meio ao nevoeiro não é possível ver o céu com seus astros e estrelas; nessas condições, navegar não é preciso. A epígrafe escolhida para abrir a terceira parte é "Pax in Excelsis".

Como observamos anteriormente, o objeto de análise deste estudo encontra-se no núcleo do brasão de Portugal, onde temos a cruz formada pelos cinco escudos e esse é o quinto poema. Fernando Pessoa estudou, discutiu e publicou sobre numerologia, astrologia, cabala, iniciação dos Rosacruzes, maçonaria, alquimia, entre outros aspectos do misticismo e do ocultismo; ${ }^{38}$ isso tudo no contexto português do início do século XX. Certamente, em Mensagem, o poeta não faria uma exposição objetiva e direta sobre esses assuntos, antes compôs versos que exigem reflexão, conhecimento e empenho de seu leitor. Cinco é um número que remete à escola de Pitágoras, em que encontramos o pentagrama como símbolo, "Depois de ter inscrito o pentágono em um círculo, com a

\footnotetext{
${ }^{34}$ PESSOA. Mensagem, p. 65.

${ }^{35}$ As ilhas mencionadas podem ser a Grã-Bretanha - o palco das histórias do Graal -, ou a ilha das Ninfas de Camões - onde Vasco da Gama encontra sua fortuna -, ou ainda aquelas das quais fala Homero contando as aventuras de Odisseu -, porque são ilhas que se assemelham culturalmente, embora haja exceção, como a ilha do Ciclope.

${ }^{36}$ Segundo os críticos Dalila L. Pereira da Costa e Agostinho Silva, ambos citados por José Augusto Seabra, o poeta insinua-se como sendo o terceiro. SEABRA. Fernando Pessoa ou o poetodrama, p. 159. Não há, de fato, um título para esse poema, entretanto, todos os poemas são numerados.

${ }^{37}$ Trecho do poema "Nevoeiro" de Mensagem.

${ }^{38}$ Dentre as obras de Fernando Pessoa sobre os temas mencionados destacamos: As origens e Essência da maçonaria e Poesias Ocultistas. Há estudos sobre os poemas de Pessoa em que se privilegiam os temas citados, como por exemplo, MESQUITA. Fernando Pessoa: o ocultismo na ótica poética.
} 
ajuda da régua e do compasso, eles puderam contemplar a estrela-do-mar (...) que eles utilizam entre si como signo de reconhecimento". ${ }^{39}$ Ainda na antiguidade, a simbologia do número cinco esteve associada aos quatro elementos essenciais (terra, água, ar e fogo) e o quinto, identificado como o espírito, ou a quinta essência dos alquimistas e agnósticos.

Robert Bonnell, em seu estudo sobre A divina comédia de Dante, afirma que o pentágono estrelado, que serviu de emblema à escola de Pitágoras, é símbolo do microcosmo humano e que as estrelas em geral representam o espírito ou o triunfo do espírito sobre a matéria e das forças da luz sobre as forças das trevas. Sua complexa análise, que tem como base a Cabala e a simbologia dos números, acompanha verso a verso a trajetória de Dante, do Inferno, passando pelo Purgatório para alcançar o Paraíso, onde encontra sua amada Beatriz, os anjos e os Bem-aventurados que formam a Cândida Rosa, no Empíreo ou décimo céu. ${ }^{40} \mathrm{Na}$ alquimia d'A divina comédia a transmutação é espiritual, da alma que movida pelo amor - a quinta essência - conquista a vida eterna.

Por essas associações, então, vamos ler: $\mathrm{O}$ encoberto,

Que símbolo fecundo / Vem na aurora ansiosa? / Na Cruz Morta do Mundo / A Vida que é a Rosa. / Que símbolo divino / Traz o dia já visto? / Na Cruz, que é o destino, / A Rosa que é o Cristo. / Que símbolo final / Mostra o sol já desperto? / na Cruz morta e fatal / A Rosa do Encoberto. ${ }^{41}$

Na poética camoniana, Vênus, a deusa da manhã, com eficientes argumentos no conselho divino, convenceu o juiz supremo, Zeus, a permitir que os lusitanos conquistassem o mar e conhecessem a terra. Afrodite dos gregos e astro maior de Camões, Vênus, em parceria com o deus alado do amor, Eros, encantou as filhas do Mar, para que elas, as Ninfas, guiassem e protegessem os navegantes portugueses. Camões, que se propôs a compor uma memória dos feitos virtuosos e dignos, inspirado pelas Musas, ornamentou com guirlandas de multicoloridas flores, sobretudo rosas, a deusa e as Ninfas, divinas personagens de Os Lvsíadas. De acordo com o poeta lusitano, é na Ilha dos Afortunados, um lugar de natureza paradisíaca com fontes cristalinas e flores diversas, onde Afrodite e as filhas de Nereu acolhem os heróis da navegação de Portugal.

Sugerimos, neste estudo, que o símbolo fecundo, divino, que surge na aurora, a Rosa possa ser interpretado como a estrela da manhã de Camões, Vênus. Podemos argumentar que, nesse poema, Pessoa fala do passado, quando diz o dia já visto, e contempla uma história de um tempo em que a navegação no mar se realizava através da observação do céu e do conhecimento sobre seus astros, de um tempo em que a geração da vida estava sob a regência de Afrodite e de Eros.

Apesar das restrições da Inquisição, Camões revela, ao compor seus versos, seu acervo de leitura e seu diálogo com as obras da antiguidade. Em Os Lvsíadas, Eros, o deus que está sempre ao lado de Afrodite, é uma criança que brinca na Via Láctea

\footnotetext{
${ }^{39}$ JACQUEMARD. Pitágoras e a harmonia das esferas, p. 150.

${ }^{40}$ BONNELL. Dante: o grande iniciado. Uma mensagem para os tempos futuros.

${ }^{41}$ PESSOA. Mensagem, p. 68.
} 
acendendo as estrelas. A vida e o brilho das estrelas são despertados pelo cupido certeiro e, neste gesto do deus menino, bem como nas qualidades de Afrodite, podemos identificar uma semelhança entre a composição camoniana e a tradição poética grega arcaica. Para nós, não há dúvida, portanto, sobre o intenso diálogo que Fernando Pessoa estabelece em Mensagem com Camões e, seja por esse intermédio ou outro, com a poesia grega antiga.

Se, na tradição antiga, as divindades femininas ocupam lugar importante na trama poética observada e se, mesmo com as restrições inquisitoriais, Camões exalta as habilidades de Afrodite e seu séquito, parece razoável então, questionar uma cultura construída no Ocidente que encobriu, com o tecido da religião cristã romana, a luz das poderosas deusas de outrora.

Carlo Ginzburg, na obra História noturna: decifrando o Sabá, revela que os rituais sagrados de culto à fertilidade da Antiguidade foram traduzidos, pela visão ideológica dos clérigos inquisidores, como culto ao Diabo. Ideologia que usou o medo como principal instrumento retórico - com uso das palavras - e físico - com as torturas no corpo dos acusados. O medo, afirma Jean Delumeu, foi o artifício mais utilizado pelo poder eclesiástico na época medieval; o medo do Inferno, do Diabo e do Juízo Final, forjou normas de conduta e novos valores culturais nas sociedades ocidentais. Esses estudos, que privilegiaram a perspectiva a longa duração na história, revelam que as mulheres ocupavam, de fato, lugares importantes dentro da religiosidade dita pagã, o que representava uma ameaça ao poder instituído pela Igreja Católica da Idade Média. ${ }^{42}$

Haquira Osakabe apresenta sua leitura do conjunto da obra de Fernando Pessoa argumentando que o projeto literário do poeta é uma "resposta à decadência" da cultura ocidental com raízes na cristandade romana. A criação heteronímia, o nascimento de Caeiro e dos seus companheiros discípulos, bem como a exaltação do neopaganismo como uma religião que preza a observação da natureza são, dentro da proposta literária de Pessoa, respostas a essa falência do cristianismo na história do Ocidente, segundo compreende Osakabe. O conjunto da obra de Fernando Pessoa não deve, contudo, ser compreendido como sendo monolítico e coeso, adverte Haquira. ${ }^{43}$

De fato, em Mensagem, o poeta coloca bastante tinta cinza em seu pincel, esse é o tom que predomina em sua crítica à religiosidade portuguesa, essencialmente Católica Apostólica Romana. Nos versos do poema "O das Quinas", Pessoa fala claramente da violência com a qual o catolicismo se impôs no Ocidente, “... foi com desgraça e com vileza / Que Deus ao Cristo definiu; / assim o opôs à Natureza...”. ${ }^{44}$ No poema, as quinas - que formam a cruz, o núcleo do brasão português - denunciam a violência com que se

\footnotetext{
${ }^{42}$ Duby, em sua obra Eva e os Padres: damas do século XII, percebe que as mulheres foram preferencialmente perseguidas pelos inquisidores, principalmente as ditas feiticeiras e as belas jovens capazes de encantar, seduzir os homens; elas, obviamente, representavam uma ameaça aos interesses do poder eclesiástico.

${ }^{43}$ OSAKABE. Fernando Pessoa, resposta à decadência.

${ }^{44}$ PESSOA. Mensagem, p. 10.
} 
formou essa cristandade romana, religiosidade que é oposta à natureza, ao amor, à quinta essência de Dante. ${ }^{45}$

Em sua leitura da obra de Walter Benjamin, filósofo contemporâneo a Fernando Pessoa e que também fez severas críticas à cultura cristã Ocidental, Susan Buck-Morss observa que,

(...) os antigos deuses foram proscritos como "pagãos" por uma cristandade triunfante, deixando atrás de si uma natureza despojada do espírito divino que uma vez os havia animado. Em contraste, a nova religião acreditava na mortificação da carne e na natureza culpada. ${ }^{46}$

Em seu profícuo diálogo com a poesia grega, Fernando Pessoa multiplicou sua voz e, nas composições de Alberto Caeiro, podemos ler o próprio paganismo nos versos em que moldou suas palavras tendo como matéria-prima a Natureza; ele falou, com a beleza da liberdade métrica, sobre as flores, as árvores e os prados, sobre as coisas do Céu e da Terra-Mãe, “(...) As minhas irmãs as plantas, / As companheiras das fontes, as santas / A quem ninguém reza...”; ${ }^{47}$ reinventou a história do menino Jesus, a eterna criança que dorme na alma do poeta, brinca com seus sonhos e ri do seu sono. Um menino que descreve sua família assim:

O seu pai era duas pessoas - / Um velho chamado José, que era carpinteiro, / E que não era pai dele; / E o outro pai era uma pomba estúpida, / A única pomba feia do mundo / Porque não era do mundo nem pomba. / E a sua mãe não tinha amado antes de o ter. Não era mulher: era uma mala / Em que ele tinha vindo do céu. / E queriam que ele, que só nascera da mãe / E nunca tivera pai para amar com respeito, Pregasse a bondade e a justiça! (...) Tudo no céu é estúpido como a Igreja Católica. ${ }^{48}$

O diálogo com a poesia grega fica explícito, também, nas odes de Ricardo Reis em que podemos: sentir a presença viva das deidades do Olimpo, escutar a flauta calma de Pã, observar o carro de Apolo rodar, ver o pôr do sol no mar, despedir-nos do triste dia moribundo e sonhar com a deusa clara. ${ }^{49}$ Ainda em Reis,

(...) Para além das esferas... / Assim choram os deuses. / Coroai-me de rosas, corai-me em verdade / De rosas - / Rosas que se apagam / Em fronte a apagar-se / Tão cedo! / Coroaime de rosas / E de folhas breves. / E basta. / O Deus Pã não morreu, / Cada campo que

\footnotetext{
${ }^{45}$ Entretanto, as quinas do brasão resguardam outros significados inerentes a essa imagem. Se a cruz é para essa Igreja de Roma, o locus da morte, do sacrifício do cordeiro de Deus para purificação dos pecados dos homens, seu significado é mais amplo e, em outro registro cultural, ela traz o sentido da união do feminino com o masculino, ato que possibilita a geração de vida. A cruz, em várias culturas, como afirma Durand, simboliza a união dos contrários, é signo de totalização do mundo, em sua forma suástica está ligada ao devir lunar astral, ao equivalente esquartelado da roda (DURAND. As estruturas antropológicas do imaginário, p. 329-330). E, ainda sobre a cruz, Fernando Pessoa diz que ela é a dupla essência de Deus, masculino e feminino (PESSOA. Poesias ocultistas, p. 39).

${ }^{46}$ BUCK-MORSS. Dialética do olhar: Walter Benjamin e o projeto das Passagens, p. 206.

${ }^{47}$ PESSOA. O guardador de rebanhos e outros poemas. Poesia Completa de Alberto Caeiro, p. 58.

${ }^{48}$ PESSOA. O guardador de rebanhos e outros poemas. Poesia Completa de Alberto Caeiro, p. 45.

${ }^{49}$ PESSOA. Obra poética, p. 255. Breve paráfrase da Ode 314 de Ricardo Reis.
} 
mostra / Aos sorrisos de Apolo / Os peitos nus de Ceres - / Cedo ou tarde vereis / Por lá aparecer / O deus Pã, o imortal (...)..$^{50}$

Poeta da Rosa e das flores, do Céu, da Terra e do Mar, Fernando Pessoa descarrega na Mensagem todo seu desencanto com a história da cultura portuguesa e manifesta sua utopia traduzida no sonho do Quinto Império, como fechamento de um ciclo e, ao mesmo tempo, é o retorno ao início; não um retorno no tempo e no espaço, mas sim uma necessidade de trazer a luz dos antigos conhecimentos para clarear a história. Dizer que Pessoa queria ser grego ou aquilo que imaginava ser grego, como afirmou Perrone-Moisés, ${ }^{51}$ soa como uma pretensão ingênua do poeta. Tal como um pescador de pérolas e corais como descreve Hanna Arendt se referindo a Walter Benjamin - Fernando Pessoa mergulha fundo no mar da história para trazer ao presente não o passado, mas extrair os "fragmentos do pensamento" e compreender o processo de cristalização shakespeareano, a transformação marinha que ocorreu nas profundezas. ${ }^{52} \mathrm{O}$ retorno cíclico não é uma repetição do passado, mas um novo ciclo que se inicia - uma nova cultura que se semeia na história.

E ainda na perspectiva dos quatro tempos de Mensagem, podemos imaginar a cruz e a estrela que se formam dentro de um círculo subdividido em quatro e identificar a imagem da rosa-dos-ventos, entre outros diversos instrumentos - de direção, de localização no espaço e de medição do tempo - desenvolvidos por diferentes sociedades em que temos, exatamente, o círculo subdividido em quatro, sucessivamente, como padrão. Acrescentamos que para Pitágoras, em que o número é a essência universal das realidades, a Tétrade é a chave de toda a estrutura física e mental, sua soma resulta na Década, ou seja, na perfeição, afirma Simonne em sua análise sobre a harmonia das esferas. ${ }^{53}$

As sociedades ocidentais encobriram, com o véu da tradição religiosa da Igreja de Roma, tanto a alétheia das deusas gregas, quanto o brilho das estrelas que guiavam os navegantes. É essa memória que, segundo nossa leitura, Fernando Pessoa tece, revelando a luz da deusa através da imagem da Rosa. Portugal tem olhos gregos, olhos que fitam o mar, essa é identidade primeira dos lusitanos, como afirma Pessoa, no poema que abre Mensagem: Ulisses, o herói grego que desafiou o Mar, é o mito que fecundou a realidade portuguesa. Na história, de fato, a identidade cultural dos gregos e portugueses está fortemente relacionada à atividade da navegação.

Fernando Pessoa foi poeta intenso, de potencial criativo e crítico imensurável. Em Mensagem, ele nos fornece símbolos e significados para compreender a história de Portugal através de uma composição na qual despeja uma tormenta de críticas à cultura do Ocidente. O poeta de Mensagem lembra o anjo da história de Walter Benjamin, que olha para o passado e vê ruínas sobre ruínas, fragmentos das imagens originais se

\footnotetext{
${ }^{50}$ PESSOA. Obra poética, p. 255.

${ }^{51}$ PERRONE-MOISÉS. Fernando Pessoa, aquém do eu, além do outro, p. 204. Também discordo da perspectiva de análise adotada pela autora quando privilegia aspectos psicológicos do poeta, tais como: "masoquismo" ou "particularidades sexuais"; e, ainda, sobre a crítica em relação aos aspectos políticos da obra de Fernando Pessoa.

${ }^{52}$ ARENDT. O pescador de pérolas.

${ }^{53}$ JACQUEMARD. Pitágoras e a harmonia das esferas, p. 147-148.
} 
amontoando, uma tempestade, ou o que chamamos de progresso, o impele para o futuro, suas asas estão abertas e o forte vento o impede de voltar. ${ }^{54}$ Segundo Konder, Benjamin afirma que “... somos sobreviventes de uma destruição paulatina de todos os grandes valores antigos, que foram aviltados e transformados em escombros pela mercantilização da vida". ${ }^{55}$ Em Pessoa encontramos, por isso, a melancolia nos versos em que diz, "Screvo meu livro à beira-mágoa. / Meu coração não tem que ter. / Tenho meus olhos quentes de água. / (...) / Ah, quando quererás, voltando. / Fazer minha esperança amor? / Da névoa e da saudade quando?". ${ }^{56}$ Ele, o anjo, “... gostaria de deter-se para acordar os mortos e juntar os fragmentos". 57

Em sua Mensagem, Fernando Pessoa reúne fragmentos da história do Ocidente, subdividindo o tempo em quatro, o que pode ser compreendido como a finalização de uma era, sendo que o por vir, o quinto, é um reinício em uma perspectiva cíclica. Afirmar que a Rosa é a imagem de Afrodite em Mensagem seria destituir a arte de sua essência, de seu caráter clássico, de ser aberta a múltiplas leituras e interpretações. Mas, é possível afirmar, do ponto de vista físico, que atrás de toda rosa existe uma estrela de cinco pontas. Que a rosa é a flor perfeita ${ }^{58}$ e que o cálice - nome científico da parte que envolve e protege o botão da rosa -, quando se abre, tem a forma de uma estrela.

Uma pesquisa sobre a presença do imaginário grego em Mensagem, com maior amplitude em relação à história - em uma perspectiva inevitavelmente de longa duração, já que é assim que o poeta compõe seu enredo -, tendo como objeto de análise a Rosa, me parece um desafio necessário, apesar de perigoso. Contudo, a relação da história com a poesia sempre foi assim, arriscada, tanto quanto caminhar a beira da falésia, como define Roger Chartier. ${ }^{59}$ Os poetas, afirma Lins Brandão em sua leitura da obra de Luciano de Samósata, possuem a pura liberdade, e os historiadores uma liberdade restrita ao que aconteceu, apesar das relações perigosas que historiadores, como Heródoto, estabelecem com os mûthos. ${ }^{60}$ É que Heródoto, apesar de não confiar no canto das sereias, não quer deixar de ouvi-lo, mesmo que para isso tenha que se amarrar em algum mastro feito de lógos. Heródoto é o paradigma de narrador, e, segundo Benjamin, não propõe uma história-síntese. ${ }^{61}$ Assim, nessa perspectiva de narrativa, tecemos nossas considerações sobre a Rosa e a mensagem que fica, por ora, desse poeta que foi vários, é a de que precisamos afastar a névoa para compreendermos outras formas de relação da humanidade com o sagrado.

\footnotetext{
${ }^{54}$ Walter Benjamin escreveu sobre o anjo da história em BENJAMIN. Sobre o conceito de história, p. 226.

${ }^{55}$ KONDER. Walter Benjamin. O marxismo e a melancolia, p. 28.

${ }^{56}$ PESSOA. Mensagem, p. 73.

${ }^{57}$ BENJAMIN. Sobre o conceito de história, p. 226.

${ }^{58}$ Da perspectiva física, a rosa é considerada pelos biólogos como uma flor perfeita, pois é composta “(...) de quatro conjuntos foliáceos: o cálice, a corola, os estames e os pistilos. O cálice é formado de pequenas sépalas verdes, que protegem as partes internas do botão. A corola é o grupo de pétalas, que varia bastante em forma e cor." (http://diariodonordeste.globo.com/materia.asp?codigo=606635).

${ }^{59} \mathrm{CHARTIER}$. À beira da falésia. A história entre certezas e inquietudes.

${ }^{60}$ BRANDÃO. O historiador no espelho do poeta.

${ }^{61}$ BENJAMIN. O narrador.
} 


\section{A B S TR A C T}

From a comparative reading between Fernando Pessoa's composition, specially of Mensagem and the greek poem Archaic where we can find images of Aphrodite - verses from Hesiod and Safo about birth and the qualities of the godess -, the objective of this article is to analyse the Rose. Through the dialogue between history and literature, the proposed discussion permeates the similariteis found between Rose of Mensagem and the godess Aphrodite from Hesiod and Safo.

\section{KEYWORDS}

Rose, Aphrodite, Mensagem

\section{REFERÊNCIAS}

ARENDT, Hanna. O pescador de pérolas. In: . Homens em tempos sombrios. Trad. Denise Bottmann. São Paulo: Companhia das Letras, 1997. p. 165-176.

BACZKO, Bronislaw. Imaginação social. Trad. Manuel Villaver de Cabral. In: ENCICLOPÉDIA EINAUDI. v. 5. Lisboa: Imprensa Nacional - Casa da Moeda, 1985. p. 296-332.

BENJAMIN, Walter. Sobre o conceito de história. In: - Magia e técnica, arte e política: ensaios sobre a literatura e historia da cultura. Trad. Sergio Paulo Rouanet. Obras escolhidas. v. 1. 7. ed. São Paulo: Brasiliense, 1994a.

BENJAMIN, Walter. O narrador. In: - Magia e técnica, arte e política: ensaios sobre a literatura e historia da cultura. Trad. Sergio Paulo Rouanet. Obras escolhidas. v. 1. 7. ed. São Paulo: Brasiliense, 1994b.

BRANDÃO, Jacyntho Lins. O historiador no espelho do poeta. In: . A poética do Hipocentauro: literatura, sociedade e discurso ficcional em Luciano de Samósata. Belo Horizonte: Editora UFMG, 2001. p. 33-50.

BONNELL, Robert. Dante: o grande iniciado. Uma mensagem para os tempos futuros. Trad. Fúlvio Lubisco. São Paulo: Masdras, 2005. 624 p.

BUCK-MORSS, Susan. Dialética do olhar: Walter Benjamin e o projeto das Passagens. Trad. Ana Luiza de Andrade. Belo Horizonte: Editora UFMG; Chapecó: Universitária Argos, 2002. 566 p.

CAMÕES, Luís de. Os Lvsíadas. Estudo Filológico de Leodegário A. de Azevedo Filho. Rio de Janeiro: Livraria Francisco Alves, 2007. (Edição fac-similada).

CHARTIER, Roger. À beira da falésia. A história entre certezas e inquietudes. Trad. Patrícia Chittoni Ramos. Porto Alegre: Editora UFRGS, 2002. 277 p.

CHANTRAINE, Pierre. Dictionnaire étymologique de la langue grecque. Histoire des motes. Paris: Klincksieck, 1999.

DELUMEAU, Jean. História do Medo no Ocidente: 1300-1800, uma cidade sitiada. 3. ed. Trad. Maria Lúcia Machado. São Paulo: Companhia das Letras, 1989. 472 p. 
DUBY, Georges. Eva e os Padres: damas do século XII. Trad. Maria Lúcia Machado. São Paulo: Companhia das Letras, 2001. 168 p.

DURAND, Gilbert. As estruturas antropológicas do imaginário. 3. ed. Trad. Hélder Godinho. São Paulo: Martins Fontes, 2002. 552 p.

GINZBURG, Carlo. História Noturna: decifrando o Sabá. 2. ed. Trad. Nilson Moulin Louzada. São Paulo: Companhia das Letras, 1991. 406 p.

HESÍODO. Teogonia. 3. ed. Estudo e Trad. Jaa Torrano. São Paulo: Iluminuras, 1995.

JACQUEMARD, Simonne. Pitágoras e a harmonia das esferas. Trad. Edgar de Assis Carvalho, Maria Perassi Bosco. Rio de Janeiro: Difel, 2007. 272 p.

KONDER, Leandro. Walter Benjamin. O marxismo e a melancolia. Rio de janeiro: Campus, 1988. 112 p.

LE GOFF, Jacques. O imaginário Medieval. 2. ed. Trad. Manuel Ruas. Lisboa: Estampa, $1994.368 \mathrm{p}$.

MESQUITA, André. Fernando Pessoa: O ocultismo na ótica poética. Rio de Janeiro: Uapê, 1996. 134 p.

OSAKABE, Haquira. Fernando Pessoa, resposta à decadência. Curitiba: Criar, 2002. 219 p. PERRONE-MOISÉS, Leyla. Fernando Pessoa, aquém do eu, além do outro. 3. ed. São Paulo: Martins Fontes, 2001. 318 p.

PESSOA, Fernando. Mensagem. 2. ed. Rio de Janeiro: Bertrand Brasil, 1989. 98 p.

PESSOA, Fernando. Poesias ocultistas. Organização, Seleção e Apresentação de João Alves das Neves. São Paulo: Aquariana, 1996. 141 p.

PESSOA, Fernando. Obra poética. In: GAlHOZ, Maria Aliete (Org.). 3. ed. / 20. reimpr. Rio de Janeiro: Nova Aguiar, 2005. 842 p.

PESSOA, Fernando. O guardador de rebanhos e outros poemas. Poesia completa de Alberto Caeiro. São Paulo: Landy, 2006. 150 p.

PESSOA, Fernando. As origens e essência da Maçonaria. São Paulo: Landy, 2006. 101 p. RAGUSA, Giuliana. Fragmentos de uma deusa. A representação de Afrodite na lírica de Safo. Campinas: Unicamp, 2005. 447 p.

RUDHARDT, Jean. Le role d'Eros et d'Aphrodite das les cosmogonies grecques. Paris: Press Universitaires de France, 1986. p. 9-40.

SANTOS, Irene Ramalho. Poetas do Atlântico. Fernando Pessoa e o modernismo angloamericano. Belo Horizonte: UFMG, 2007. 421 p.

SEABRA, José Augusto. Fernando Pessoa ou o poetodrama. São Paulo: Perspectiva, 1982. $214 \mathrm{p}$.

VERNANT, Jean-Pierre. Cosmogonia. In. . Entre mito e política. Trad. Cristina Murachco. São Paulo: Edusp, 2001. p. 239-261.

WEST, Martin L. (Ed.). Prolegomena and Commentary. In: HESIOD. Theogony. Oxford: Clarendon Press, 1966. p. 150-359.

Site: http://diariodonordeste.globo.com/materia.asp? codigo $=606635$ 